A measure of the continuing vigour of research in this field is given by the extent to which the book has been overtaken by important new discoveries during its writing. The most significant of these came with the observation in 1972 of two new and apparently superfluid phases of liquid helium three below $3 \mathrm{mK}$ thus, at a stroke, doubling the number of superfluids known in nature. The authors are to be commended for having managed to slip a page on this topic into the last chapter but, even so, the pace of advance has been such that already the passage strikes one as being principally of historical interest.

Vigorously and concisely written, the volume is lavishly adorned with diagrams and graphs of relevant experimental results, many of which will look comfortably familiar to workers in the field, but a significant number of which have not previously appeared within the pages of any textbook. There is a selection of problems at the end of each chapter except the last. In addition to references at the conclusion of each chapter, there is a select bibliography at the end of the book listing most of the standard texts and laced with descriptive comments, a number of which are amusingly barbed.

Thus in spite of one or two deficiencies, there is so much to be said on the positive side that $I$, for one, will strongly be recommending my graduate students and, indeed, some of my colleagues to read this book.

P. V. E. McClintock

\section{Analysis of rocks}

Laboratory Handbook of Petrographic Techniques. By Charles S. Hutchinson. Pp. xxvii +527 . (Wiley: New York and London, 1974.) $£ 10.60$.

THE title implies a rather unexciting prospect for the reader. Petrography is a vital part of petrology, and few scientists concerned with the genesis of rock complexes can afford to neglect the textures and mineral associations within a rock sample. Even so, it is the petrological analogue of anatomy in medicine, and has recently been in danger of neglect during the race by earth scientists to embrace geophysics and geochemistry as providing the main information for understanding the evolution of the Earth. Petrographic analysis is not essential for all geological studies, but there are few in which it does not demand an important role.

Some petrographic techniques have remained essentially $\mathrm{unch}$ ang ed throughout this century, such as polarised-light microscopy, mineral separation, and determination of specific gravity and refractive index. There have, however, been advances in method and this book presents an upto-date survey of the whole field. The real advance made here, compared with earlier books on the subject, is the inclusion of sections on X-ray diff raction, differential thermal analysis and thermoluminescence measurements, and the expansion of the con-

\section{Please take note}

Effective Technical Writing and Speaking. By Barry T. Turner. Pp. xi+206. (Business Books: London, 1974.) £4.75.

THE Professor of Industrial Management at the University of Newcastle has aimed his book at engineers and scientists in industry; there are chapters on how to write specifications, sales literature, contracts, patents and handbooks. But the sections on writing articles and reports, on organising meetings, on giving talks and how best
to illustrate them, will interest to illustrate then
academics as well.

Professor Turner's advice on all these topics is sensible and helpful. Some of it might even seem obvious, George Eliot is misquoted. And in a were it not for the incomprehensible book devoted to better writing the use handbooks, the turgid and jargon-filled of "disinterested" to mean "uninterarticles, and the ill-prepared lectures ested" is regrettable.

with illegible slides, that we are all un- In general, however, Professor happily familiar with.

Turner's book makes useful reading We are urged to avoid technical for anyone speaking or writing on jargon in our writing; to use short technical subjects. It would be a profitsentences and short Anglo-Saxon able addition to any library. words; and to approximate to con- cept of petrography by including geochemical analysis by X-ray fluorescence, atomic absorption, and other techniques for components that cannot be analysed by physical methods. An excellent chapter on "Display of Data" deals rigorously with norm calculations, variation diagrams for rocks and minerals, and the statistical analysis of data.

The book is designed as a laboratory manual, and step-by-step instructions are given for all the techniques, ranging from photomicrography to the determination of feldspar structural state, matrix corrections in XRF spectrometry, or the calculation of mineral formulae. The subjects are well illustrated, and the book makes interesting reading. The author has, in fact, been remarkably sucessful in bringing new life to an old subject, probably because he conveys the impression that each technique has been subjected to his critical usage, and because he makes lively quantitative recommendations that are difficult to fault.

There is some overlap with Physical Methods in Determinative Mineralogy (edit. by J. Zussman) and Methods in Geochemistry (edit. by A. A. Smales and L. R. Wager), although surprisingly he does not refer to the latter. Nevertheless, the emphasis of this book is different and there is no real equivalent for a research student or advanced-level undergraduate specialising in petrology. It will save supervisors and tutors many hours of routine instruction, and may extend the life expectancy of much laboratory equipment.

My major criticism of this otherwise excellent book is the inclusion of 68 pages on X-ray fluorescence spectrometry which, like electron probe analysis, is dealt with in specialist texts. The author omitted electron probe techniques partly for that reason, whereas I would view them as vital to petrographic analysis. In contrast, the section on reflected-light microscopy is absurdly brief (about 6 pages) despite its vital role in petrography and the difficulties encountered by students.

Other notable omissions, in the context of the author's aims, are singlecrystal X-ray diffraction (for example anorthite structural state), petrofabric analysis, factor analysis, electron microscopy and Mössbauer spectroscopy. Some attention to problems of zoned crystals (refractive index section) and modal analysis (for example use of reflected light), and to mineral examples (eight pages for garnets versus one third of a page for clinopyroxeies, under $\mathrm{X}$-ray diffraction) are also needed, in any revised edition.

G. M. Brown 